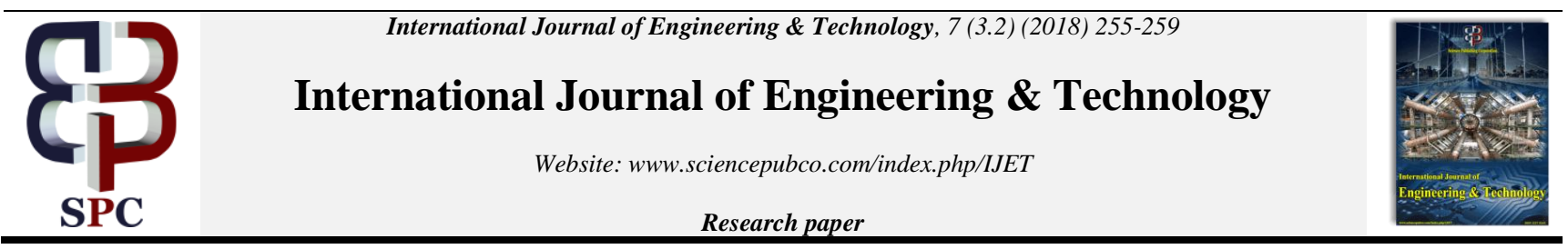

\title{
The Basic Parameters of Vibration Settings for Sealing Horizontal Surfaces
}

\author{
Ivan Nazarenko $^{1}{ }^{*}$, Mykola Ruchynskyi $^{2}$, Maksym Delembovskyi ${ }^{3}$ \\ ${ }^{1}$ Kiev National University Of The Construction And Architecture, Ukraine \\ ${ }^{2}$ Kiev National University Of The Construction And Architecture, Ukraine \\ ${ }^{3}$ Kiev National University Of The Construction And Architecture, Ukraine \\ *Corresponding Author E-Mail:I_Nazar@I.Ua
}

\begin{abstract}
Keywords: concrete mix, resonance, seals, vibration.

\section{Introduction}

In modern construction fate cast-frame method is increasingly used [1]. A large proportion of the implementation of this method is accompanied by the formation of horizontal surfaces where there is a problem of sealing. Of particular importance is the formation of horizontal surfaces in the arrangement of underground garages, units, installations and maintenance of the building etc. In this paper we solve the problem to study the dynamics of surface vehicles of considerable length $(l>2 \ldots 3 \mathrm{~m})$ in terms of interaction with the manufacturing environment.
\end{abstract}

Are examined and defined pattern vibratory motion to form horizontal surfaces on the basis of the account of wave phenomena and bias voltages. Given numerical values screeds and rheological characteristics of sealing concrete.

Based on the analysis of the energy balance, motion qualities limits are defined. Analytical dependences for the estimation of main parameters of the effective vibroimpact mode are suggested as well as the motion stability layout of the analyzed system is cited.

\section{Purpose of Work}

Of surface compaction devoted a num-ber of works [2-4]. In [2, 3] considered a discrete model of the concrete mix. Signifi-cant theoretical research based on wave theory Concrete mixture ramming surface vibration are given in $[4,5]$, which revealed the basic laws of motion of this class of machines. The results $[4,5]$ is much deeper insight into the process of consolidation. Soil compaction over Vibration rammer dedicated works [6, 7]. Based on the results of the cited studies [4-7], a similar problem is solved based on the model of the envi-ronment, taking into account the shear stress $[8,9]$, which is one of the effective compaction.

\section{Main Body}

Methodology provides premise that the concrete mixture, which is under the lining for the device horizontal surfaces are quasi homogeneous body. It is assumed that the concrete mixture is modeled flexible rod length $\mathrm{h}$. Consider that at the core of the force of gravity, which causes it to longitudinal oscillations.

If we denote by $u(x, t)$ displacement of the rod cross-section of abscissa $x$ at time $t$, then the differential equation of forced oscillations of "lining - a layer of concrete mix" considering energy dissipation is as follows: $\frac{\partial^{2} u(x, t)}{\partial x^{2}}=\frac{1}{c^{2}(1+i \gamma)} \frac{\partial^{2} u(x, t)}{d t^{2}}+g$

where $\frac{\partial^{2} u}{d t^{2}}$ and $\frac{\partial^{2} u}{d x^{2}}-$ under acceleration mixture and the second derivative of strain

$\varepsilon=\frac{\partial u(x, t)}{d x} ; i=\sqrt{-1 ;} \quad c-$ velocity of longitudinal waves propagating in a layer of concrete mixture having elastic modulus $E$ and density $\rho, c=\sqrt{\frac{E}{\rho}} ; \gamma-$ loss factor, which characterizes the energy dissipation; $\gamma=\frac{\Delta W}{2 \pi \cdot W} ; \Delta W-$ energy absorbed by the basic layer of concrete mixture over period; $W$-potential energy of deformation of this layer; $g$ - acceleration due to gravity.

Assuming that the concrete mix is an environment in which the generated elastic shear wave, and the surface of the lining is not separated from the surface layer of the concrete mix, the boundary conditions can be represented as follows:

$\left.u\right|_{x=h}=0 ;\left.u\right|_{x=0}=x_{0} \sin (\omega t)$,

where $x_{0} \equiv A$ - the amplitude of oscillation of the working body lining, $\omega$ - circular frequency of its oscillations.

We assume that the initial displacement and initial velocity is zero, then the initial conditions can be summarized as follows:

$\left.u\right|_{t=0}=0,\left.\frac{\partial y}{\partial t}\right|_{t=0}=0$ 
To address the problem (1) - (2) can not apply the Fourier method, since the boundary conditions (3) uniform. But this problem is easily reduced to a problem with zero boundary conditions (in which you can apply the Fourier method).

Indeed, we introduce a supporting role:

$$
\begin{aligned}
w(x, t)= & x_{0} \sin (\omega t)-x_{0} \sin (\omega t) \frac{x}{h}= \\
= & x_{0} \sin (\omega t)\left(1-\frac{x}{h}\right)
\end{aligned}
$$

It is clear that:

$$
\left.w\right|_{x=0}=x_{0} \sin (\omega t),\left.\quad w\right|_{x=h}=0
$$

The problem is now looking as the sum of:

$u(x, t)=v(x, t)+w(x, t)$

where $v(x, t)$ - new unknown function. Due to the boundary conditions (2), (5) and the initial conditions (3), the function $v(x, t)$ must satisfy the boundary conditions:

$\left.v\right|_{x=0}=0 ;\left.v\right|_{x=h}=0$,

and initial conditions:

$\left.v\right|_{t=0}=\left.u\right|_{t=0}-\left.w\right|_{t=0}=0$.

$$
\begin{gathered}
\left.\frac{\partial v}{\partial t}\right|_{t-0}=\left.\frac{\partial u}{\partial t}\right|_{t-0}-\left.\frac{\partial w}{\partial t}\right|_{t-0}= \\
=-\omega x_{0}+\omega x_{0} \frac{x}{h}=-\omega x_{0}\left(1-\frac{x}{h}\right) .
\end{gathered}
$$

Substituting now equation, we get:

$$
\frac{\partial^{2} v}{\partial t^{2}}=a^{2} \frac{\partial^{2} v}{\partial x^{2}}+g+a^{2} \frac{\partial^{2} w}{\partial x^{2}}-\frac{\partial^{2} w}{\partial t^{2}}
$$

or by virtue of (4),

$\frac{\partial^{2} v}{\partial t^{2}}=a^{2} \frac{\partial^{2} v}{\partial x^{2}}+g(x, t)$,

where,

$g(x, t)=g-\omega^{2} x_{0} \sin (\omega t)\left(1-\frac{x}{h}\right)$.

In (10) and (11) introduce the notation:

$a^{2}=c^{2}(1+i \gamma)$.

Thus, we obtain the problem for the function $v(x, t)$ :

$$
\left\{\begin{array}{l}
\frac{\partial^{2} v}{\partial t^{2}}=a^{2} \frac{\partial^{2} v}{\partial x^{2}}+g(x, t), \\
\left.v\right|_{x=0}=0 ;\left.v\right|_{x=h}=0, \\
\left.v\right|_{t=0}=0 ;\left.\frac{\partial v}{\partial t}\right|_{t=0}=-\omega x_{0}\left(1-\frac{x}{h}\right),
\end{array}\right.
$$

$v(x, t)=v_{1}(x, t)+v_{2}(x, t)$,

where $v_{1}(x, t)$ is a solution of the inhomogeneous equation:

$$
\frac{\partial^{2} v_{1}}{\partial t^{2}}=a^{2} \frac{\partial^{2} v_{1}}{\partial x^{2}}+g(x, t)
$$

Satisfying the boundary conditions:

$$
\left.v_{1}\right|_{x=0}=0 ;\left.v_{1}\right|_{x=h}=0
$$

and initial conditions:

$\left.v_{1}\right|_{t=0}=0 ;\left.\frac{\partial v_{1}}{\partial t}\right|_{t=0}=0$,

and $v_{2}(x, t)$, is a solution of a homogeneous equation:

$\frac{\partial^{2} v_{2}}{\partial t^{2}}=a^{2} \frac{\partial^{2} v_{2}}{\partial x^{2}}$

Meets the boundary conditions:

$\left.v_{2}\right|_{x=0}=0 ;\left.\quad v_{2}\right|_{x=h}=0$,

and initial conditions:

$\left.v_{2}\right|_{t=0}=0$,

$\left.\frac{\partial v_{2}}{\partial t}\right|_{t=0}=-\omega x_{0}\left(1-\frac{x}{h}\right)$

Decision $v_{1}(x, t)$ is the forced oscillation layer of concrete mixture, and oscillations that occur under external exciting force, if the initial perturbations are absent.

Decision $v_{2}(x, t)$ is the free oscillation layer of concrete mixture, and fluctuations which occur only as a result of the initial perturbation.

Using [3], we have to $v_{2}(x, t)$, :

$$
\left\{\begin{array}{l}
v_{2}(x, t)=\sum_{k=1}^{\infty}\left(a_{k} \cos \left\{\frac{k \pi a t}{h}\right\}+b_{k} \times\right. \\
\left.\left.\times \sin \left\{\frac{k \pi a t}{h}\right\}\right) \sin \left\{\frac{k \pi x}{h}\right\}\right) \\
a_{k} \equiv 0, b_{k}=\frac{2}{k \pi a} \times \\
\times \int_{0}^{h}\left\{-\omega x_{0}\left(1-\frac{x}{h}\right)\right\} \sin \left\{\frac{k \pi x}{h}\right\} d x .
\end{array}\right.
$$

For $v_{1}(x, t)$ can find a solution in the form of the following series:

$$
v_{1}(x, t)=\sum_{k=1}^{\infty} T_{k}(t) \sin \left(\frac{k \pi x}{h}\right),
$$

where,

We will seek a solution to this problem as the sum of: 


$$
\begin{aligned}
& T_{k}(t)=\frac{2}{h \omega_{k}} \times \\
& \times \int_{0}^{1} d r \int_{0}^{h} g(x, \tau) \sin \left[\omega_{k}(t-r)\right] \times \\
& \times \sin \left(\frac{k \pi \xi}{h}\right) d \xi, \omega_{k}=\frac{k \pi a}{h} . \\
& v(x, t)=\sum_{k=1}^{\infty} T_{k}(t) \sin \left(\frac{k \pi x}{h}\right)+ \\
& +\sum_{k=1}^{\infty}\left\{a_{k} \cos \left[\frac{k \pi a t}{h}\right]+b_{k} \sin \left[\frac{k \pi a t}{h}\right]\right\} \times \\
& \times \sin \left[\frac{k \pi x}{h}\right] .
\end{aligned}
$$

The first term in (25) is a layer of concrete mix fluctuations, caused by the presence of gravity and magnitude of the effect of the working body surface lining for placement of horizontal surfaces with zero initial conditions.

The second term in (25) is a layer of concrete mix fluctuations, caused by the presence of non-zero initial conditions.

Table 2, 3 presents values $\omega_{k}, s^{-1}$ for $\mathrm{k}=1,2,3$ and different values of $h, \mathrm{~m}, \mathrm{a}, \mathrm{m} / \mathrm{s}$.

In the case of resonance $\left(\omega=\omega_{k}\right)$ the time during which an increase of the amplitude of the movement in the layer of concrete mix is determined by the approximate relation:

$$
t_{\text {incr. }}=\frac{2}{\gamma \omega}
$$

For typical values of $\omega$ (see Tab. 1) and $\gamma(\gamma=0,1 \ldots 0,3), t_{\text {incr. }}$ is $(0.01 \ldots 0 \ldots 0.02) \mathrm{s}$.

\begin{tabular}{|c|c|c|c|c|c|c|c|c|}
\hline \multirow{2}{*}{$\begin{array}{l}\text { Para- } \\
\text { meter }\end{array}$} & \multicolumn{2}{|c|}{$\begin{array}{c}\text { Perfo- } \\
\text { mance, } \\
\text { m3/h }\end{array}$} & \multirow{2}{*}{$\begin{array}{c}\text { Oscil- } \\
\text { lation } \\
\text { fre- } \\
\text { quency } \\
\mathrm{rad} / \mathrm{s}\end{array}$} & \multirow{2}{*}{$\begin{array}{c}\text { Static } \\
\text { mo- } \\
\text { ment, } \\
\mathrm{kg} \times \mathrm{m}\end{array}$} & \multirow{2}{*}{$\begin{array}{l}\text { Pow- } \\
\text { er, } \\
\text { kW }\end{array}$} & \multirow{2}{*}{$\begin{array}{c}\text { Dimen- } \\
\text { sions, } \\
\mathrm{l} \times \mathrm{b} \times \mathrm{h}\end{array}$} & \multicolumn{2}{|c|}{ Mass, kg } \\
\hline & $\mathrm{l}=2 \mathrm{~m}$ & $\begin{array}{r}1=3 \\
m\end{array}$ & & & & & $\begin{array}{c}\mathrm{l}=2 \\
\mathrm{~m}\end{array}$ & $1=3 n$ \\
\hline \begin{tabular}{|c|} 
The \\
numer- \\
ical \\
values
\end{tabular} & $\begin{array}{l}60- \\
180\end{array}$ & $\begin{array}{l}90- \\
270\end{array}$ & 314 & $\begin{array}{c}0,046 ; \\
0,058 ; \\
0,072 ; \\
0,092\end{array}$ & 0,6 & $\begin{array}{c}2(3) \times 0,4 \times \\
0,27\end{array}$ & 52 & 72,8 \\
\hline
\end{tabular}

As a result of solving the problem of survey was requested and made screeds $1=2 \mathrm{~m}, 1=3 \mathrm{~m}$ and $1=4 \mathrm{~m}$, are put into production. Specifications of screed $1=3 \mathrm{~m}$ and $1=4 \mathrm{~m}$ are shown in Tab. 2

Table 1: The numerical values

\begin{tabular}{|c|c|c|c|c|c|c|c|c|c|}
\hline \multirow{2}{*}{$\begin{array}{c}\mathrm{h}, \\
\mathrm{m}\end{array}$} & \multicolumn{3}{|c|}{$\mathrm{a}=20 \mathrm{~m} / \mathrm{s}$} & \multicolumn{3}{c|}{$\mathrm{a}=40 \mathrm{~m} / \mathrm{s}$} & \multicolumn{3}{c|}{$\mathrm{a}=60 \mathrm{~m} / \mathrm{s}$} \\
\cline { 2 - 10 } & 1 & 2 & 3 & 1 & 2 & 3 & 1 & 2 & 3 \\
\hline 0,1 & 228,3 & 125,7 & 188,5 & 125,7 & 251,3 & 377,0 & 188,5 & 377,0 & 565,5 \\
\hline 0,15 & 218,9 & 237,8 & 125,7 & 237,8 & 167,6 & 251,3 & 125,7 & 251,3 & 377,0 \\
\hline 0,2 & 314,2 & 228,3 & 242,6 & 228,4 & 125,7 & 188,5 & 242,6 & 188,5 & 282,8 \\
\hline
\end{tabular}

Table 2: Specification screeds

For determination of the energy is necessary to make the equation of energy balance, for this work A, performed by external force $\mathrm{F}(\mathrm{t})$ at time $\mathrm{T}$, equivalent to the total dissipative energy losses in the system at the same time [10]. These losses consist of: viscous losses in the nodes of the machine; dissipation of energy when hitting the limiter of oscillations; the energy lost to seal the concrete mix for the period of oscillation $\mathrm{T}$. Based on these assumptions, we can write the expression for work:

$$
\begin{aligned}
& A=\int_{0}^{T}\left(c_{v e}+c_{\text {eq.post. }}+c_{\text {eq.p. }}\right) \dot{x} d t+ \\
& +\left(1-R^{2}\right) A_{k}+A_{\delta}
\end{aligned}
$$

where $\mathrm{R}$ - factor recovery rate when hitting the limiter of oscillations; $A_{k}$ - kinetic energy of the form with concrete mix before hitting of the limiter of oscillations; $A_{k}=\left[m_{\delta}+m_{\delta}^{\prime}\right] \dot{x}^{2}\left(\tau_{1}\right) / 2 ; c_{v e}-$ equivalent stiffness losses in viscoelastic vibration nodes of machine; $A_{\delta}$ - average height $h$ mix work for the period $\mathrm{T}$, which lost in the consolidation of this mixture.

Assume designations:

$\eta_{\mu}=c_{v e}+c_{\text {eq.post. }}+c_{\text {eq.p. }}$

Find work $A_{\delta}$ in accordance with the equations of motion of the mixture and expression for the contact force [10]. Elementary work $F_{\text {eq. fric. }}$ of friction in the mix:

$$
d A_{\delta}=F_{e q . f r i c .} d u=\gamma_{\delta} \frac{\partial^{2} u(y, t)}{\partial y \cdot \partial t} d u
$$

where $\gamma_{\delta}$ - coefficient characterizing energy loss in the mixture, $u(y, t)$-moving in layers of mix.

Because

$d u=\frac{d u}{d y} d y+\frac{d u}{d t} d t$

then (29) can be written:

$$
d A_{b}=\frac{\gamma_{\delta} \cdot \partial^{2} u}{\partial y \cdot \partial t} \cdot\left[\frac{d u}{d y} d y+\frac{d u}{d t} d t\right]
$$

The first term that depending brackets (30) describes work in elementary layer of concrete mix, which is connected with its deformation, and the second term - with the movement of a single layer The average value of losses on the height of the product in one period of the movement (30), we obtain the expression:

$$
\begin{aligned}
& A_{\delta}=\frac{1}{T} \frac{1}{h} \int_{0}^{h} d y \int_{0}^{T} d t\left[\int_{0}^{h} \frac{\gamma_{\delta} \partial^{2} u}{\partial y \partial t} \frac{d u}{d y} d y+\right. \\
& \left.+\int_{0}^{T} \frac{\gamma_{\delta} \partial^{2} u(y, t)}{\partial y \partial t} \frac{d u}{d t} d t\right]
\end{aligned}
$$

In consideration of equivalent (average) values of amplitude after simple transformations (31) we have:

$$
A_{\delta}=\int_{0}^{T} n_{\delta} \dot{x}^{2} d t,
$$

Where

$$
\begin{aligned}
& n_{\delta}=2 R_{e}\left\{\frac { \gamma _ { \delta } e ^ { - 2 z } } { [ 1 + e ^ { - 2 z } ] ^ { 2 } } \left[\frac { 1 } { 2 } \left(\frac{z}{i 2 \pi h}+\right.\right.\right. \\
& \left.\left.\left.+\frac{1}{h}\right)\left(e^{2 z}-e^{-2 z}\right)-\frac{2 z^{2}}{i 2 \pi h}\right]\right\}, \\
& z=h\left(\alpha_{1}+i \beta_{1}\right) \\
& \alpha_{1}=\frac{\omega_{a v .}}{c_{\delta}^{4} \sqrt{1+\gamma_{\delta}^{2}}} \cos \left[\frac{1}{2} \operatorname{arctg}(-\gamma)\right] \\
& \beta_{1}=\frac{\omega_{a v .}}{c_{\delta}^{4} \sqrt{1+\gamma_{\delta}^{2}}} \sin \left[\frac{1}{2} \operatorname{arctg}(-\gamma)\right] .
\end{aligned}
$$


The formula (33) is much simpler if you accept some conditions. For example, for

$|\mathrm{z}|>>1$ :

$n_{\delta}=\gamma_{\delta} \cdot \frac{\left|\beta_{1}\right|}{2 \pi} ;$

for $|\mathrm{z}| \ll<1$ : in general terms $n_{\delta}=f(h)$.

Thus the energy balance equation can be folded in a way that limits the possible vibration amplitude will be determined by the upper - viscosity effects, and bottom - the shock dissipation. In the case under consideration, vibration resistant operation will be when $\omega_{a v .}=\omega$ :

$$
\begin{aligned}
& \frac{1}{2} \cdot \frac{\left(m_{1}+m_{\delta}^{\prime}\right)}{\left(m_{\delta}^{\prime}\right)} \leq q \leq \\
& \leq \sqrt{\frac{m_{1} \omega(1+R)}{8 \pi\left(n_{i}+n_{\delta}\right)(1+R)}} ; \xi>\frac{1}{2}
\end{aligned}
$$

In the case of abruption vibrator and mixture $\xi>1 / 2$ is selected from those provisions, leading to shock-vibration mode in the system and then had realized one hit in one period of movement. When conditions (35) the average of the amplitude of vibration will be determined from the following relationship:

$$
\begin{aligned}
& \frac{F_{0}}{2\left(n_{\delta}+n_{m}\right) \omega}\left\{1-\sqrt{1-\frac{4 q^{2}\left(n_{\delta}+n_{m}\right) \cdot c^{*}}{\omega}}\right\} \leq \\
& \leq A_{s r .} \leq \\
& \leq \frac{F_{0}}{2\left(n_{\delta}+n_{m}\right) \omega}\left\{1+\sqrt{1-\frac{4 q^{2}\left(n_{\delta}+n_{m}\right) \cdot c^{*}}{\omega}}\right\}
\end{aligned}
$$

$$
\text { where } c^{*}=2 \pi(1-R) /\left[m_{1}(1+R)\right] \text {. }
$$

Calculations by the formulas (35) in relation machines for seal concrete mix give range for values: $0,6 \leq \mathrm{q} \leq 1,5$ and $1,4 \leq \xi \leq 2,5$ [7]. Thus for the criteria $\mathrm{q}$, which determines the balance of power, the value $\mathrm{q} \approx 1,0 \ldots 1,5$ corresponds criteria $\xi$, which has the value $\xi=0,8 . .1,3$. This is the first (Fig. 3) zone of stability, which in terms of selection parameters more suitable in certain accurately mass characteristics. This area is sensitive to changes of mass in the process of movement of the shockvibration installation. The zone of stability at $q \approx 0,6 \ldots 0,7$, which corresponds to $\xi=2,0 \ldots 2,5$, requires less power loss, but the amplitude spectrum may decrease, which follows from the analysis of the formula (36). Map of stability (Fig.1), built for a wide range of parameters, confirms the possible existence of several zones (at least three for installation of forming units) of stability.

In Tab. 3 are shown numerical values of performance parameters of vibration-shock process to determine their effect at the time of impact $t_{\text {imp }}$.

Calculations that are made for resulted parameter values (Tab. 1) show that for the acceleration coefficient $a_{\max }=(4 \ldots 5) g$ at coefficient of restoration of speed $K v=0,3 \ldots 0,4$ time of impact is equal to $t_{i m p .}=(0,015 \ldots 0,01) s$, that is for the frequency,

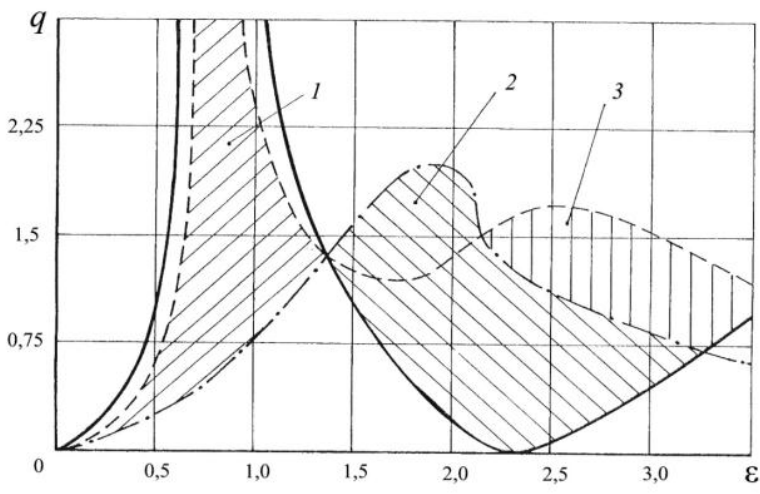

Fig. 1: Map stability of motion of the shock vibration systems: 1 - first zone, 2 - second zone, 3 - third zone

Table 3: Limits change of parameters of vibration-shock process

\begin{tabular}{|c|c|c|c|}
\hline $\begin{array}{c}\text { Acceleration in } \\
\text { the destiny, } \\
\text { amax/g }\end{array}$ & $\begin{array}{c}\text { Dimensionless } \\
\text { coefficient } \\
\text { of resistance, } \\
\delta\end{array}$ & $\begin{array}{c}\text { Coefficient of } \\
\text { speed recovery, } \\
\mathrm{Kv}\end{array}$ & $\begin{array}{c}\text { Time of } \\
\text { blow, } \\
\text { tyд.10-2, s }\end{array}$ \\
\hline $3 \ldots 10$ & $0,045 \ldots 0,3$ & $0,3 \ldots 0,8$ & $1,5 \ldots 1,95$ \\
\hline
\end{tabular}

$\omega=157 \mathrm{~s}^{-1}$ ratio $\frac{\tau}{T}=0,358 \ldots 0,238$ which determines the effect of intense acceleration on the process of compaction. An important characteristic that affects the parameter $K_{t}=\tau / T$, as at the time of contact is coefficient of stiffness.

\section{Conclusion}

1. In the case of application of vibration impacts are commonly used to determine the dependence of the calculated viscosity require considerable refinement: necessary to account for vibration, and in some cases the inertial forces of resistance fluctuations.

2. To ensure that the products of good quality (horizontal surface), where the presence of cavities and shells kept to a minimum, you must set the mode vibro-formation concrete mixes, which are inherent limitations to the vibration amplitude.

3. The basic laws of motion of a concrete mixture is compacted surface lining in the process of improvement of concrete horizontal surfaces, methods of mathematical physics, and held valid in terms of mathematics, the procedure for obtaining general solution of equations, allowing full use of the Fourier method.

4. Dependences should be used in the improvement and refinement of engineering calculations such systems in order to optimize them and to improve the quality furnished horizontal surfaces.

5. Formulated energy balance, realizing the impact-vibration mode mixed discrete-continuous system of movement.

6. Getting analytical dependences for definition of rational parameters of workflow and new different from main resonance, movement stable zones of contribution of higher harmonics.

\section{References}

[1] Sviderskiy A.T. 2013. The study of the dynamics of vibrating machines based on the stress-strain state of elastic-plastic medium. Vinnytsya. Vibrations in engineering and technology. №3 (71), 41 45.

[2] Dedov O.P. 2006. Mathematical model and determine the parameters of vibration ram for soil compaction. Gìrničì, budìvelnì, dorožnì ta melìorativnì mašini [Mining, constructional, road and melioration machines], $\mathrm{Nr} 66,41-46$.

[3] Zapryvoda A.V., Ruchynskiy M.M. 2013. Study of the basic characteristics of the process of forming horizontal surfaces working body vibration. Kyiv. Theory and practice of building. Nr12, 44-47.

[4] Runova R.F., Gots V.I., Nazarenko I.I. and others. 2008. Materials of construction of a new generation and technologies introduction. Kyiv. UVPK, Eks 05, 360. 
[5] Rudenko I.F. 1972. Formation of products of surface vibrator. Moskow, Stroyizdat, 104.

[6] Savinov O.A., Lavrinovich E.V. 1986. Vibrating machinery seals molding concrete mixtures. Leningrad. Stroyizdat, 280.

[7] Harnets V.M. 1991. Advanced units and complexes. Kyiv, Builder, 144.

[8] Chubuk Y.F., Nazarenko I.I., Harnets V.N. 1985. Vibrating machines for compacting concrete mixtures. Kyiv, Higher school, Head publishing house, 165.

[9] Goldshteyn B.G., Petrun'kin L.P. 1966. Vibrators for compacting concrete. Moskow, Engineer, 172.

[10] Nazarenko I.I., Ruchynskyy M.M. 2013. Energy ratio in shock vibration machines for seal concrete mixes. Vinnytsya, Vibrations in engineering and technology, №3 (71), 67-71.

[11] Nazarenko I.I. 2007. Vibrating machines and processes of the construction industry. Kyiv, KNUCA, 230.

[12] Nazarenko I.I. 2010. Applied Problems vibration systems theory (2nd Edition), Kyiv, Publishing House Word. 440.

[13] Nazarenko I.I, Ruchynskyy M.M. 2002. Physical principles of mechanics of building materials, Lviv, Poster, 128.

[14] Sivko V.I. 1988. Fundamentals of mechanics of vibrating concrete, Kyiv. Higher school, 168.

[15] Osmakov S.A., Braude F.G. 1972. Vibro-shock forming machines, Moskow, Stroyizdat, 152.

[16] Osmakov S.A. 1964. Motion Study of vibrating platform with a form of freely resting on the elastic pad. Tr. VNIIGS, Moskow, Leningrad. Producing 17, with 105-111.

[17] Goncharevich I.F., Sergeev P.A. 1963. Vibrating machine construction, Moskow, Engineering, 311.

[18] Mariusz Saniak. 2014. Energy Balance of a Prosument Microinverter On-Grid Photovoltaic System. Teka Komisji Motoryzacji i Energetyki Rolnictwa Vol. XIV-3, Poland, 99-103.

[19] Krzysztof Necka. 2013. Selection of decisive variables for the construction of typical end user power demand profiles. Teka Komisji Motoryzacji i Energetyki Rolnictwa, Vol.XIII-2, Poland, 67-72.

[20] Anna Nikolaenko, Alsayyad Taha Hussein. 2014. Modelling of vibrating machine-tool with improved construction. Teka Komisji Motoryzacji i Energetyki Rolnictwa, Vol.XIV-1, Poland, 174-181.

[21] Korobko B. (2016), Investigation of energy consumption in the course of plastering machine's work, Eastern-European Journal of Enterprise Technologies, 4/8 (82), 4 - 11. DOI: 10.15587/17294061.2016.73336. 